\title{
Inpatient cost of treating osteoporotic fractures in mainland China: a descriptive analysis
}

This article was published in the following Dove Press journal:

ClinicoEconomics and Outcomes Research

13 April 2015

Number of times this article has been viewed

\section{Yicheng Yang' \\ Fen $\mathrm{Du}^{2}$ \\ Wenyu $\mathrm{Ye}^{3}$ \\ Yu Chen ${ }^{4}$ \\ Jinghu $\mathrm{Li}^{5}$ \\ Jie Zhang ${ }^{6}$ \\ Helen Nicely ${ }^{7}$ \\ Russel Burge ${ }^{8}$}

'Patient Outcomes and Real World Evidence, Lilly Suzhou Pharmaceutical Co, Ltd, Shanghai, ${ }^{2}$ Pharmacoeconomics and Outcomes Research, Beijing Brainpower Pharma Consulting Co, Ltd, Beijing, People's Republic of China; ${ }^{3}$ Real World Analytics Bio-Medicines, Eli Lilly and Company, Indianapolis, IN, USA; ${ }^{4}$ Medical Department, Lilly Suzhou Pharmaceutical Co, Ltd, Shanghai, ${ }^{5}$ Secretariate, ${ }^{6} \mathrm{Technology}$ Standard Department, China Health Insurance Research Association, Beijing, People's Republic of China; ${ }^{7}$ Medical Writing, inVentiv Health Clinical, San Francisco, CA, ${ }^{8} \mathrm{Global}$ Patient Outcomes and Real World Evidence, Bio-Medicines, Eli Lilly and Company, Indianapolis, IN, USA
Correspondence: Russel Burge Eli Lilly and Company, Lilly Corporate Center, Drop Code I542, Indianapolis, IN 46285, USA

Tel +I 3172779530

Fax + I 3172770490

Email rburge@lilly.com
Purpose: The objective of this study was to provide new estimates on the per-admission inpatient hospital cost and per-admission length of stay (LOS) for osteoporosis-related fractures in mainland China.

Materials and methods: Data for inpatient hospitalization associated with at least one osteoporosis-related fracture were obtained from the nationwide China Health Insurance Research Association and were analyzed post hoc. Patients' data were included if the patients were $\geq 50$ years old and diagnosed with osteoporosis and pathologic fracture, or osteoporosis therapy and fragility fracture by an International Statistical Classification of Diseases and Related Health Problems, 10th Revision (ICD-10) code designation, between 2008 and 2010.

Results: The analysis included 830 patients (female: $77.3 \%$; mean age: $73.4 \pm 9.8$ years). The medians of the per-admission LOS and inpatient costs were 19 days and $¥ 18,587$, respectively. Longer LOS and higher costs per admission were associated with older patients ( $\geq 70$ years) compared to younger patients ( $<70$ years). Hip fracture had the longest median LOS ( 22 days) and highest median cost ( $¥ 32,594)$ among all fracture sites. The per-hospitalization episode and per-day costs of osteoporotic fracture increased rapidly ( $60 \%$ and $89 \%$, respectively) between 2008 and 2010.

Conclusion: The analysis showed that hospitalization cost increases were associated with increasing per-day hospitalization costs. The proportion of the costs reimbursed by health insurances increased, while the mean absolute patient copayment amounts decreased. The incidence and prevalence of osteoporosis and osteoporosis-related fractures may rise rapidly due to the projected growth of the aged population in mainland China. Therefore, the combination of greater anticipated total fractures and rising hospital costs may lead to a tremendously increased economic burden in the future.

Keywords: inpatients, hospital costs, length of stay, osteoporosis burden, mainland China

\section{Introduction}

Estimates for current inpatient hospital length of stay (LOS) and costs due to osteoporotic fractures in mainland China remain relatively unknown except for four studies conducted in the years 2000, ${ }^{1} 1998-2002,{ }^{2} 1998-2003,{ }^{3}$ and $1998-2007 .{ }^{4}$ The consequences of osteoporotic fractures include increased morbidity, disability, and economic burden on the health care system and society. ${ }^{5}$ In mainland China, a regional study conducted between 2002 and 2006 of 7,042 healthy individuals aged 20 years and older estimated the number of individuals older than 50 years with a high risk of osteoporosis at 12.5 million (10.4\%) men and 37.2 million $(31.2 \%)$ women. ${ }^{6}$ Forecasts of demographic data for the $\geq 65$-year-old Chinese population indicate 
that it will more than double from 115 million in 2010 to over 238 million by $2030 .{ }^{7}$ With the rapidly growing elderly population in mainland China, osteoporosis is anticipated to become highly prevalent, and it will be increasingly important to understand current hospital costs and LOS in order to plan for a more efficient allocation of resources to meet this expected growing disease burden. The aim of this study was to provide a descriptive summary of inpatient hospital cost estimates for osteoporosis-related fractures based on an analysis of retrospective data between 2008 and 2010 for peradmission inpatient hospital costs, LOS, patient copayment burden, and per-day hospital costs in mainland China. At this time, there are no existing studies utilizing the China Health Insurance Research Association (CHIRA) claims database for estimating costs from the payer perspective.

\section{Materials and methods}

This retrospective analysis identified patients with at least one hospitalization for osteoporotic fracture between 2008 and 2010 using the CHIRA claims database. This database was chosen because it is the largest nationwide claims database in mainland China, which would provide a sufficient sample size for this analysis; it is also representative of over 70 tier 1,2 , and 3 cities in mainland China, and would balance the geographic and economic differences across mainland China. However, the CHIRA database does not include rural areas and thus is not representative of rural China. Patient data collected from the CHIRA database represented a nationwide, cross-sectional sample collected annually from inpatients of sample cities, and included demographics, hospital type and tier, diagnosis, comorbidities, medications, services and dates, LOS, and insurance type. In mainland China, there are three public health insurances: the Urban Employee Basic Medical Insurance (UEBMI); the Urban Resident Basic Medical Insurance (URBMI); and the New Rural Cooperative Medical Insurance. The UEBMI covers urban employees and the URBMI covers those who are not employed (young children, students, and unemployed urban residents). Once an enrollee has been covered by the UEBMI for more than 15 years, that individual will be covered by the same medical insurance for his or her entire life (ie, the enrollee will continue to be covered by the UEBMI after retirement).

Figure 1 presents a flowchart of patients included in this study. The inclusion criteria for this study required patients to be aged $\geq 50$ years and to have been hospitalized for osteoporotic fracture, where osteoporotic fracture was defined as a diagnosis of osteoporosis and pathologic fracture, or fragility fracture with an osteoporosis therapy. Osteoporosis with

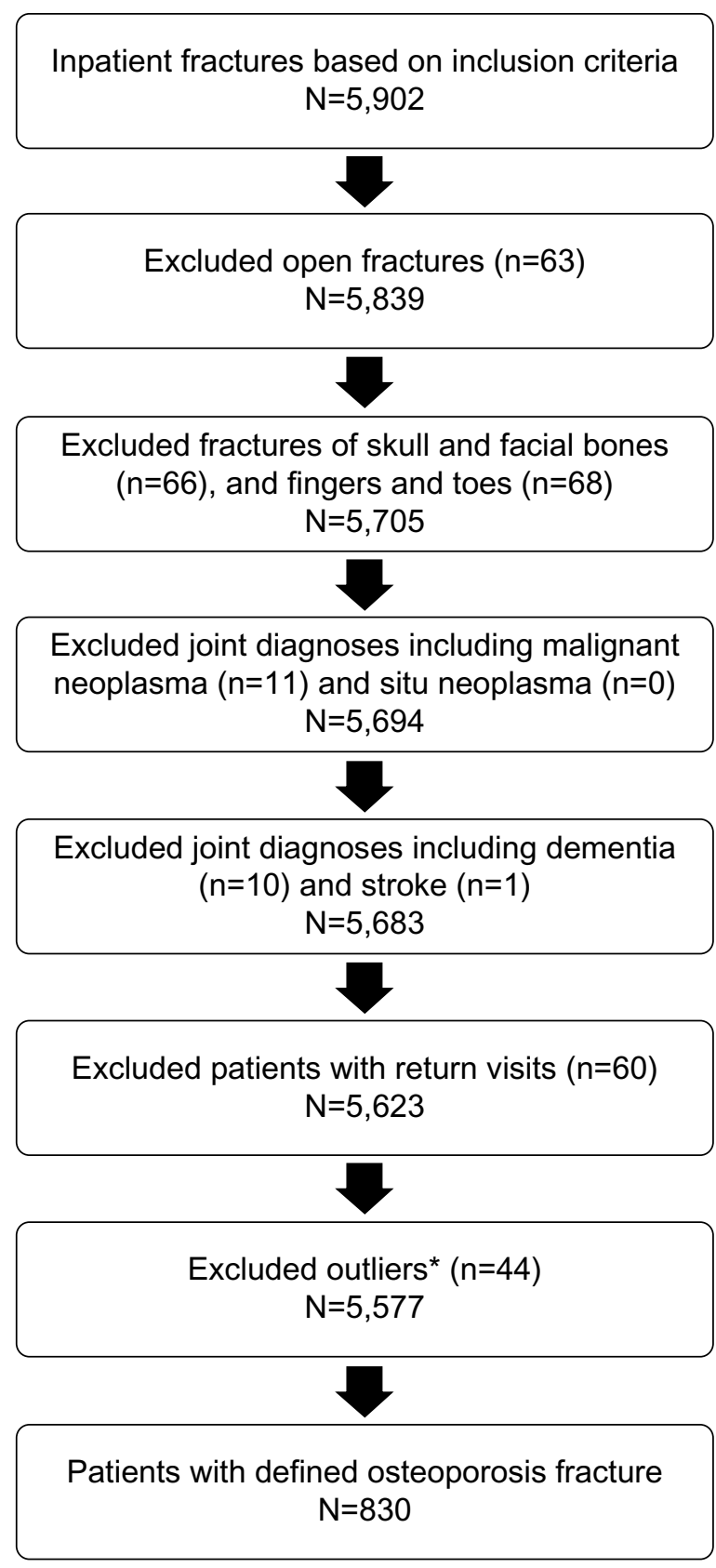

Figure I Patient flowchart.

Note: *Outliers included length of stay $>400$ days and hospitalization costs $>¥ 50,000$ or $\leq ¥ 300$.

Abbreviations: $\mathrm{N}$, total number; $\mathrm{n}$, sample number.

pathologic fracture and fragility fractures (vertebral, hip, nonvertebral/nonhip [NVNH], multiple fractures, or unspecified site of fracture) were identified by an International Statistical Classification of Diseases and Related Health Problems, 10th Revision (ICD-10) code diagnosis. The NVNH fracture sites included the humerus, femur, wrist, pelvis, rib, ankle, foot, and "others" (unspecified).

Decision rules were imposed to screen-out potential outliers due to extremely high or low resource use or costs, 
if associated with clinical conditions not due to osteoporosis. For this reason, patients with severe comorbidities (such as cancer or stroke) were excluded because such comorbidities may have significantly impacted hospitalization costs and led to extremely high cost outcomes that were unrelated to osteoporosis fractures. Specifically, patients were excluded if the LOS was $>400$ days; if hospitalization costs were $<¥ 300$ or $>¥ 500,000$; if they had comorbidities of stroke, dementia, or incurable cancers; if fractures were related to severe trauma such as car accidents or other violence; or if fractures involved the bones of the skull, face, fingers, or toes.

\section{Statistical analysis}

Descriptive statistical methods were used to produce a profile of patients' baseline characteristics, fracture sites, and hospitalization years for osteoporotic fracture patients. To account for non-normally distributed data, Wilcoxon rank-sum tests (for two groups) and the Kruskal-Wallis test (for $>2$ groups) ${ }^{8}$ were used to test and compare the LOS and total medical costs among different subgroups of osteoporotic fracture inpatients (sex, age group, and fracture sites).

The significance level was set at $\alpha=0.05$, and all analyses were conducted using StataSE (version 12) and Microsoft Excel (Microsoft Corporation, Redmond, WA, USA).

\section{Results}

\section{Patient demographics}

Overall, based on the inclusion criteria, there were 830 patients with osteoporotic fractures requiring hospitalization during 2008 and 2010 (Table 1). Of the total, females comprised $77.3 \%$, the patients' mean age was $73.4 \pm 9.8$ years, and nearly $70 \%$ were at least 70 years old. Approximately $82 \%$ were covered by UEBMI, whereas $17 \%$ were covered by URBMI; 9 a small percentage, $1.3 \%$, could not be identified with respect to insurance type. Representation by area and city level was disproportionately highest in the east $(83.7 \%)$ and in provincial capitals/municipalities $(81.5 \%)$, respectively. Approximately two-thirds of patients were treated in tier 3 hospitals.

\section{Fracture sites}

The distribution of total fractures by year was $13 \%, 31 \%$, and 56\% from 2008-2010 (Table 2). Over the full 3-year period, the distribution of osteoporotic fractures by type was $32.5 \%$ (number $[n]=270), 30.8 \%(n=256)$, and $31.9 \%(n=265)$ for vertebral, hip, and NVNH, respectively. The within-year distribution of fractures by type remained relatively stable over
Table I Osteoporotic fracture patient demographics

\begin{tabular}{lll}
\hline $\begin{array}{l}\text { Total patients with fracture } \\
\mathbf{N}=830\end{array}$ & $\mathbf{n}$ & Distribution \\
\hline Sex & & \\
$\quad$ Male & 188 & $22.7 \%$ \\
$\quad$ Female & 642 & $77.3 \%$ \\
Age group & & \\
$\quad$ All (excluding unspecified) & 823 & - \\
Mean (SD) & $73.4(9.8)$ & \\
$50-59$ years & 92 & $11.1 \%$ \\
$60-69$ years & 152 & $18.3 \%$ \\
$70-79$ years & 350 & $42.2 \%$ \\
$80+$ years & 229 & $27.6 \%$ \\
Unspecified & 7 & $0.8 \%$ \\
Insurance type & & \\
Employed (UEBMI) & 678 & $81.7 \%$ \\
Resident (URBMI) & 141 & $17.0 \%$ \\
Unspecified & 11 & $1.3 \%$ \\
Area & & \\
East & 695 & $83.7 \%$ \\
Center & 59 & $7.1 \%$ \\
West & 76 & $9.2 \%$ \\
City level & & \\
Provincial capitals/municipalities & 676 & $81.5 \%$ \\
Prefecture/subprefecture cities & 143 & $17.2 \%$ \\
County-level cities & 11 & $1.3 \%$ \\
Hospital level & & \\
Community and township hospitals & 11 & $1.3 \%$ \\
Hospital tier & & $2.4 \%$ \\
I & 20 & $67.0 \%$ \\
2 & 243 & \\
3 & 556 & \\
\hline A & & \\
\hline
\end{tabular}

Abbreviations: $\mathrm{N}$, number of patients in group; $\mathrm{n}$, number of affected patients; $\mathrm{SD}$, standard deviation; UEBMI, Urban Employee Basic Medical Insurance; URBMI, Urban Resident Basic Medical Insurance.

the 3 years. Overall, vertebral fractures were more often lum$\operatorname{bar}(23.9 \% ; n=198)$ compared to thoracic $(8.7 \% ; n=72)$ (data not shown in table). The NVNH fractures occurred, overall, more often in the femur $(9.2 \% ; n=76)$ when compared to the humerus $(5.2 \% ; n=43)$; but, in general, the sample sizes were too small to make meaningful comparisons of the individual NVNH fracture sites (data not shown in table).

\section{Length of stay and costs associated with osteoporotic fracture}

The overall median LOS was 19 days. The median LOS was similar across sexes, but were not similar for age groups $(P=0.023)$, while statistically significant differences were found for insurance status $(P=0.002)$ and fracture site $(P=0.0001)$ (Table 3$)$. The median LOS among UEBMI was 19 days, while the median LOS for nonworking residents (covered by the URBMI) was 16 days. The highest median LOS was reported for hip fractures (22 days), and was statistically significantly greater than vertebral fracture median 
Table 2 Fracture sites per year, 2008-2010

\begin{tabular}{|c|c|c|c|c|c|c|c|c|c|c|c|}
\hline \multirow[t]{2}{*}{ Fracture site } & \multicolumn{2}{|l|}{ Total } & \multicolumn{3}{|l|}{2008} & \multicolumn{3}{|l|}{2009} & \multicolumn{3}{|l|}{2010} \\
\hline & $\begin{array}{l}\mathbf{N}=830 \\
\mathrm{n}\end{array}$ & $\%$ & $\begin{array}{l}N=107 \\
n\end{array}$ & $\begin{array}{l}\text { Within } \\
2008 \\
\%\end{array}$ & $\begin{array}{l}\text { Over } 3 \text { years } \\
2008-2010 * \\
\%\end{array}$ & $\begin{array}{l}N=255 \\
n\end{array}$ & $\begin{array}{l}\text { Within } \\
2009 \\
\%\end{array}$ & $\begin{array}{l}\text { Over } 3 \text { years } \\
2008-2010 * \\
\%\end{array}$ & $\begin{array}{l}N=468 \\
n\end{array}$ & $\begin{array}{l}\text { Within } \\
2010 \\
\%\end{array}$ & $\begin{array}{l}\text { Over } 3 \text { years } \\
2008-2010 * \\
\%\end{array}$ \\
\hline Vertebral & 270 & $32.5 \%$ & 31 & $29.0 \%$ & $11.5 \%$ & 83 & $32.5 \%$ & $30.7 \%$ & 156 & $33.3 \%$ & $57.8 \%$ \\
\hline Hip & 256 & $30.8 \%$ & 33 & $30.8 \%$ & $12.9 \%$ & 93 & $36.5 \%$ & $36.3 \%$ & 130 & $27.8 \%$ & $50.8 \%$ \\
\hline NVNH & 265 & $31.9 \%$ & 33 & $30.8 \%$ & $12.5 \%$ & 78 & $30.6 \%$ & $29.4 \%$ & 154 & $32.9 \%$ & $58.1 \%$ \\
\hline Multiple fractures & 6 & $0.7 \%$ & 2 & $1.9 \%$ & $33.3 \%$ & I & $0.4 \%$ & $16.7 \%$ & 3 & $0.6 \%$ & $50.0 \%$ \\
\hline Unspecified & 33 & $4.0 \%$ & 8 & $7.5 \%$ & $24.2 \%$ & 0 & $0.0 \%$ & $0.0 \%$ & 25 & $5.3 \%$ & $75.8 \%$ \\
\hline
\end{tabular}

Note: *Percent values calculated as the current year fracture total divided by the 3-year total for the specific fracture type.

Abbreviations: $\mathrm{N}$, number of patients in group; n, number of affected patients; $\mathrm{NVNH}$, nonvertebral/nonhip.

LOS ( 15 days; $P<0.0001)$ and greater than NVNH fracture median LOS (18 days; $P<0.0001)$.

For per-admission costs, the median cost for inpatient hospital fractures was $¥ 18,587$. Median hospital costs were higher for men than for women ( $¥ 20,391$ versus $¥ 17,787$, respectively), but they were not statistically significantly different $(P=0.1454)$. By age, median costs ranged from $¥ 14,623$ in the 50-59-year age group to $¥ 21,930$ in the 80 +-year age group, but the differences were not statistically significantly different $(P=0.0852)$. Median costs were different among UEBMI-insured employees; URBMI-insured, nonworking residents; and the nonspecified ( $¥ 19,479$, $¥ 16,418$, and $¥ 1,305$, respectively; $P=0.0353$ ). By fracture site, hip fractures had the highest median cost $(¥ 32,594)$ when compared to NVNH fractures ( $¥ 17,185)$ and vertebral fractures $(¥ 10,493)(P<0.0001)$. The median cost differences between fracture sites were all statistically significant.

\section{Yearly trends in length of stay and medical costs associated with osteoporotic fractures}

Over the 3 years, the mean hospital LOS showed a slight decrease of approximately 9\%, from 24.1 days in 2008 to 21.9 days in 2010 (Table 4). In contrast, the estimated mean hospital costs revealed a large increase of almost $60 \%$ from 2008 to 2010, with most of the increase occurring between 2008 and 2009 (44\% increase from $¥ 16,696$ to $¥ 24,056$ ) (Figure 2 ). Along with the increasing hospital costs, insurance reimbursement increased as a proportion of the total payment, while the patient proportion of the total payment decreased. In 2008, reimbursement by the UEBMI and URBMI for osteoporotic fractures was, on average, approximately $¥ 8,655$ or $52 \%$ ( $¥ 8,655 / ¥ 16,696$ ). By 2010 , the UEBMI and URBMI share of reimbursement rose to approximately $61 \%$ ( $¥ 16,242 / ¥ 26,701$ ). The share of hospital payments borne by individuals fell from $48 \%$ in 2008 to $39 \%$ in 2010 (Table 4). However, on average, the absolute copayment amounts paid by individuals increased by $30 \%$ from $¥ 8,041$ in 2008 to $¥ 10,460$ in 2010 . On a per-day basis, the average hospital costs were estimated to rise from $¥ 802$ in 2008 by $74.3 \%$ to $¥ 1,397$ in 2009 , and by $89.2 \%$ to $¥ 1,517$ in 2010 (Figure 3).

To provide more information pertaining to the most recent data, an additional analysis of the 468 patients in 2010 showed the median LOS was 18 days for UEBMI versus 15 days for URBMI, and the highest median hospital cost was $¥ 38,746$ for hip fracture (Table 5).

\section{Discussion}

This retrospective database study analyzed CHIRA claims data from 2008-2010 to estimate hospital costs and LOS due to osteoporotic fractures reported in mainland China. The median hospital LOS and inpatient costs for all fractures were 19 days and $¥ 18,587$, respectively. Older fracture patients ( $\geq 70$ years) had longer median per-admission LOS of 19 days $(P<0.01)$ and higher median costs of reimbursement of $¥ 21,528(P<0.01)$ than younger patients. Hip fractures had the longest median LOS (22 days) and highest median cost ( $¥ 32,594)$. We also found a sharp increase in the mean hospital costs of over $44 \%$ and $60 \%$ from 2008 to 2009 and from 2008 to 2010, respectively, while the corresponding mean costs per day rose by over $74 \%$ and $89 \%$ during these periods. In addition, patient copayment, as a percentage of hospital costs, fell by $6.1 \%$ in 2010 (39.2\%) compared to 2009 (45.3\%), but due to overall rising hospital costs, the patients' total out-of-pocket burden increased by $30 \%$.

Hospital distribution was geographically unequal; there were $695(83.7 \%)$ hospitals located in the east, $59(7.1 \%)$ located in the center, and $76(9.2 \%)$ located in the west. Therefore, the results and conclusions from the pooled data reported herein may not be completely applicable to all areas. 
Table 3 Hospital length of stay and hospitalization costs by patient characteristics, insurance type, and fracture type, 2008-20I0

\begin{tabular}{|c|c|c|c|c|c|c|c|c|}
\hline & $\mathbf{N}$ & Mean \pm SD & Median & Max & Min & Range & $\begin{array}{l}\text { P-value } \\
\text { (Kruskal-Wallis) }\end{array}$ & $\begin{array}{l}\text { P-value } \\
\text { (Wilcoxon) }\end{array}$ \\
\hline Total & 830 & $22.5 \pm 18.3$ & 19 & 181 & I & 180 & & \\
\hline Sex & & & & & & & & 0.478 \\
\hline Male & 188 & $21.5 \pm 16.1$ & 18 & 126 & 4 & 122 & & \\
\hline Female & 642 & $22.8 \pm 19.0$ & 19 & 181 & I & 180 & & \\
\hline Age group & & & & & & & 0.023 & \\
\hline $50-59$ years & 92 & $21.0 \pm 17.7$ & 17 & 99 & I & 98 & & \\
\hline $60-69$ years & 152 & $21.6 \pm 19.0$ & 17 & 126 & 2 & 124 & & $0.138^{\mathrm{a}}$ \\
\hline $70-79$ years & 350 & $23.4 \pm 18.7$ & 19 & 181 & I & 180 & & 0.312 \\
\hline $80+$ years & 229 & $22.6 \pm 17.8$ & 19 & 126 & 1 & 125 & & \\
\hline Unspecified & 7 & $14.9 \pm 8.5$ & 14 & 31 & 6 & 25 & & \\
\hline Insurance type & & & & & & & 0.002 & \\
\hline Employed (UEBMI) & 678 & $23.3 \pm 19.1$ & 19 & 181 & 1 & 180 & & \\
\hline Resident (URBMI) & $|4|$ & $18.7 \pm 13.9$ & 16 & 93 & I & 92 & & \\
\hline Unspecified & 11 & $24.6 \pm 13.3$ & 27 & 43 & 7 & 36 & & \\
\hline Fracture sites & & & & & & & 0.0001 & \\
\hline Vertebral & 270 & $20.2 \pm 17.6$ & 15 & 126 & I & 125 & & $<0.000 \mathrm{I}^{\mathrm{b}}$ \\
\hline Hip & 256 & $27.1 \pm 19.4$ & 22 & 181 & 2 & 179 & & $<0.000 \mathrm{I}^{\mathrm{c}}$ \\
\hline NVNH & 265 & $21.1 \pm 18.3$ & 18 & 177 & I & 176 & & $0.0528^{d}$ \\
\hline Multiple fractures & 6 & $18.2 \pm 13.4$ & 13.5 & 43 & 8 & 35 & & \\
\hline Unspecified & 33 & $17.7 \pm 8.0$ & 16 & 35 & 5 & 30 & & \\
\hline \multicolumn{9}{|l|}{ Hospital costs ( $¥)$} \\
\hline Total & 830 & $24,599 \pm 22,064$ & 18,587 & $|56,50|$ & 352 & & & \\
\hline Sex & & & & & & & & 0.1454 \\
\hline Male & 188 & $27,452 \pm 25,542$ & 20,391 & $|56,50|$ & 374 & & & \\
\hline Female & 642 & $23,763 \pm 20,886$ & 17,787 & 133,700 & 352 & & & \\
\hline Age group & & & & & & & 0.0852 & \\
\hline 50-59 years & 92 & $19,623 \pm 17,976$ & 14,623 & 95,590 & 2,215 & & & \\
\hline $60-69$ years & 152 & $22,670 \pm 23,347$ & 15,530 & $|56,50|$ & 484 & & & $0.1767^{\mathrm{a}}$ \\
\hline $70-79$ years & 350 & $26,205 \pm 22,542$ & 21,091 & 133,700 & 915 & & & 0.6983 \\
\hline $80+$ years & 229 & $25,626 \pm 21,899$ & 21,930 & 127,196 & 352 & & & \\
\hline Unspecified & 7 & $17,966 \pm 12,255$ & 11,358 & 35,656 & 5,559 & & & \\
\hline Insurance type & & & & & & & 0.0353 & \\
\hline Employed (UEBMI) & 678 & $25,45 \mathrm{I} \pm 21,992$ & 19,479 & $|46,48|$ & 837 & 145,643 & & \\
\hline Resident (URBMI) & $|4|$ & $22,298 \pm 22,214$ & 16,418 & $|56,50|$ & 944 & 155,556 & & \\
\hline Unspecified & 11 & $1,608 \pm 1,235$ & 1,305 & 3,983 & 352 & 3,631 & & \\
\hline Fracture sites & & & & & & & 0.0001 & \\
\hline Vertebral & 270 & $19,239 \pm 20,503$ & 10,493 & 120,813 & 374 & 120,439 & & $<0.000 \mathrm{I}^{\mathrm{b}}$ \\
\hline Hip & 256 & $34,202 \pm 22,867$ & 32,594 & 133,700 & 837 & 132,863 & & $<0.000 \mathrm{I}^{\mathrm{c}}$ \\
\hline NVNH & 265 & $22,034 \pm 20,084$ & 17,185 & $|56,50|$ & 529 & 155,972 & & $0.0046^{d}$ \\
\hline Multiple fractures & 6 & $27,513 \pm 35,265$ & 8,905 & 80,077 & 352 & 79,725 & & \\
\hline Unspecified & 33 & $13,440 \pm 15,195$ & 8,599 & 57,325 & 983 & 56,343 & & \\
\hline
\end{tabular}

Notes: a Comparison of inpatients aged 60-69 years versus those aged 80+ years; 'bomparison of vertebral fracture versus hip fracture; 'comparison of hip fracture versus $\mathrm{NVNH}$ fracture; ${ }^{\mathrm{d}}$ comparison of NVNH fracture versus vertebral fracture. Exchange rate $=1 \mathrm{RMB} / \mathrm{CNY}=0.16$ USD.

Abbreviations: N, number of patients in group; SD, standard deviation; Max, maximum; Min, minimum; UEBMI, Urban Employee Basic Medical Insurance; URBMI, Urban Resident Basic Medical Insurance; NVNH, nonvertebral/nonhip; RMB, Renminbi; CNY, Chinese Yuan; USD, United States dollar.

A few previous studies have reported estimates on hospital costs and LOS for fracture patients in large cities in mainland China. Retrospective data on hospital LOS and costs in the year 2000 for 2,855 patients aged 50 years and older (mean age: $73.6 \pm 9.9$ years) who were hospitalized for bone fragility hip fractures in 13 districts of Shanghai,
People's Republic of China, were obtained from hospital records and were analyzed by Dai et al. ${ }^{1}$ The mean LOS for osteoporotic women was 35 days, but was longer for patients aged over 60 years and was associated with a higher mean cost of hospital stay ( $¥ 18,932$, up from $¥ 15,082$ ) at age $65-74$ years. Only $14 \%$ of patients hospitalized for osteoporotic hip 
Table 4 Yearly trends in length of stay and costs, 2008-2010

\begin{tabular}{|c|c|c|c|c|c|}
\hline \multirow[t]{3}{*}{$\mathbf{N}=\mathbf{8 3 0}$} & \multicolumn{5}{|c|}{ Defined osteoporosis fractures $(\mathrm{N}=830)$ by day } \\
\hline & \multicolumn{5}{|c|}{ Hospital length of stay (days) } \\
\hline & Mean \pm SD & Median & Max & Min & Range \\
\hline Total & $22.5 \pm 18.3$ & 19 & 181 & I & 180 \\
\hline \multicolumn{6}{|l|}{ Year } \\
\hline 2008 & $24.1 \pm 16.6$ & 21 & 100 & I & 99 \\
\hline 2009 & $22.9 \pm 18.2$ & 19 & 96 & I & 95 \\
\hline 2010 & $21.9 \pm 18.8$ & 18 & 181 & I & 180 \\
\hline \multicolumn{6}{|c|}{ Hospital costs ( $¥)$} \\
\hline 2008 & $16,696 \pm 19,416$ & 10,234 & 127,196 & 352 & 126,844 \\
\hline 2009 & $24,056 \pm 20,673$ & 19,817 & 126,287 & 837 & 125,450 \\
\hline 2010 & $26,70 I \pm 22,963$ & 21,349 & $|56,50|$ & 944 & 155,556 \\
\hline \multicolumn{6}{|c|}{ UEBMI and URBMI cover (reimbursement) } \\
\hline 2008 & $8,655 \pm 9,911$ & 4,783 & 50,605 & 19.3 & 50,585 \\
\hline 2009 & $13,160 \pm 13,270$ & 7,992 & 85,454 & 191 & 83,263 \\
\hline 2010 & $|6,242 \pm| 7,36 \mid$ & 9,002 & 105,179 & 0.7 & 105,178 \\
\hline \multicolumn{6}{|c|}{ Individual medical economic burden (copayment) } \\
\hline 2008 & $8,041 \pm 16,062$ & 1,025 & 124,604 & 0.00 & 124,604 \\
\hline 2009 & $10,896 \pm 14,475$ & 4,954 & 85,326 & 0.00 & 85,326 \\
\hline 2010 & $10,460 \pm 15,777$ & 4,722 & $153,4 \mid 3$ & 0.00 & $153,4 \mid 3$ \\
\hline \multicolumn{6}{|c|}{ Hospital costs per day } \\
\hline 2008 & $802 \pm 862$ & 506 & $4,74 \mid$ & 35.3 & 4,706 \\
\hline 2009 & $1,397 \pm 1,629$ & 985 & 14,956 & 53 & 14,902 \\
\hline 2010 & $1,517 \pm 1,779$ & $\mathrm{I}, 045$ & 27,260 & 90.8 & 27,169 \\
\hline
\end{tabular}

Note: Exchange rate $=$ I RMB/CNY $=0.16$ USD.

Abbreviations: SD, standard deviation; Max, maximum; Min, minimum; UEBMI, Urban Employee Basic Medical Insurance; URBMI, Urban Resident Basic Medical Insurance; RMB, Renminbi; CNY, Chinese Yuan; USD, United States dollar.

fracture received treatment for osteoporosis. Another study of hip fracture costs and LOS over 6 years in Shanghai, People's Republic of China, was reported by Huang et al. ${ }^{3}$ While the average costs for femoral neck fracture increased from $¥ 13,115$ in 1998 up to $¥ 25,867$ in 2003 , and the average costs for intertrochanteric fracture increased from $¥ 8,678$ in 1998 up to $¥ 19,098$ in 2003 , the LOS for both groups did not change significantly (ranging between 16 days and 24 days) during the same 6-year period.

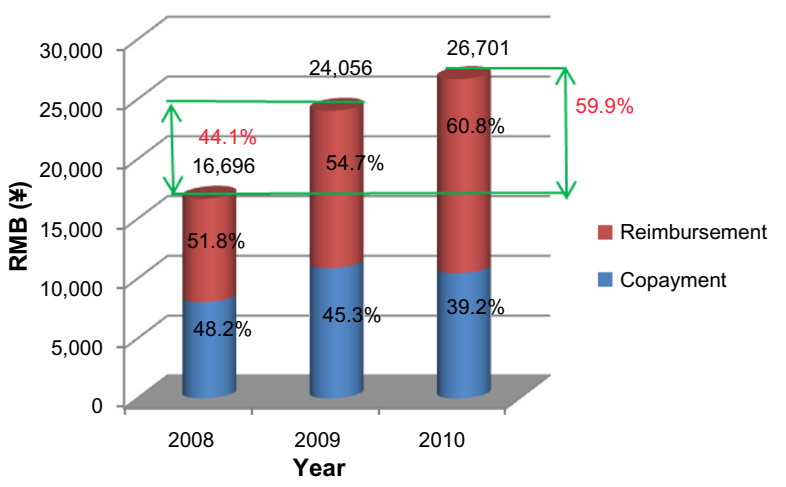

Figure 2 Average per-admission hospitalization costs and patient copayment by year. Abbreviation: RMB, Renminbi.

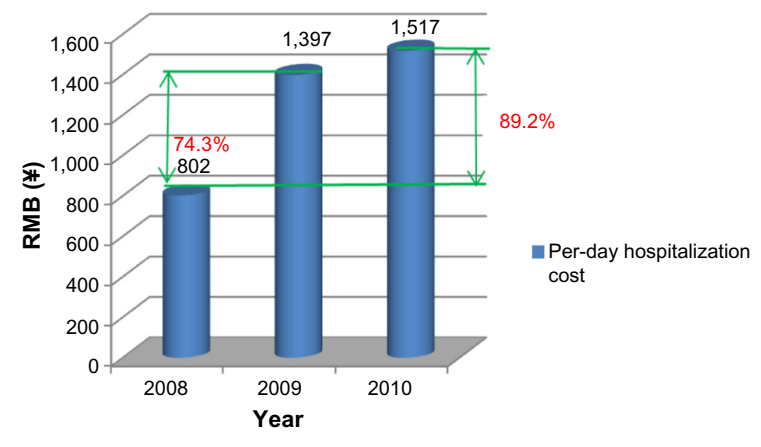

Figure 3 Average per-day hospitalization costs by year. Abbreviations: RMB, Renminbi.

Similarly, Luo and $\mathrm{Xu}^{2}$ analyzed data from 90 patients with osteoporotic hip fracture who completed a questionnaire from Peking Union Medical College Hospital (Beijing, People's Republic of China), following discharge between 1998 and 2002. There were 90 patients (29 males) and the mean \pm standard deviation (SD) average age was $71.78 \pm 9.7$ years. The annual economic burden per patient was $¥ 32,776$, of which the hospital cost was $¥ 23,107$, and it comprised $70.5 \%$ of the total cost. Unfortunately, this analysis did not present LOS data.

Another study by Cheng et $\mathrm{al}^{4}$ reported on 3,449 osteoporotic hip fracture patients (average mean \pm SD age: $76.32 \pm 9.52$ years) who were discharged from two hospitals in Guangzhou, People's Republic of China, during the period between 1998 and 2007. The mean \pm SD LOS was $23.59 \pm 13.48$ days and hospitalization costs increased, on average, by $6.18 \%$ each year over the study period. The average (mean \pm SD) inpatient costs were $¥ 23,520 \pm ¥ 17,000$ and they were associated mostly with treatment (implants and materials used in surgery and wound care [52\%], pharmacy intervention [25\%], surgery [6\%], ward expenditure [5\%], radiology and physical investigation [5\%], and chemistry testing [4\%]). While hospitalization numbers peaked for the 70-79-year (38.45\%) and 80-89-year (33.08\%) age groups, inpatient costs peaked for the 60-69-year age group, with overall costs correlated significantly with LOS.

All of these fracture-cost studies predate the period of this current study, and none used nationally derived data; therefore, direct comparisons were not possible in most cases. However, for osteoporotic hip fractures occurring in mainland China, these studies indicate a similar escalation in treatment costs that were correlated with LOS.

An important strength of our study is that it used recent, nationally representative hospital data to derive new estimates on hospital LOS and costs due to osteoporotic fractures. The study provides detailed estimates by fracture 
Table 5 Length of stay and hospitalization costs per admission, 2010

\begin{tabular}{|c|c|c|c|c|c|c|c|c|c|c|}
\hline & \multicolumn{5}{|c|}{ Length of stay in $2010(\mathrm{~N}=468)$ (days) } & \multicolumn{5}{|c|}{ Hospitalization cost in $2010(\mathrm{~N}=468)(¥)$} \\
\hline & Mean \pm SD & Median & Min & Max & $\begin{array}{l}\text { P-value } \\
\text { (Wilcoxon) }\end{array}$ & Mean \pm SD & Median & Min & Max & $\begin{array}{l}\text { P-value } \\
\text { (Wilcoxon) }\end{array}$ \\
\hline Total & $21.9 \pm 18.8$ & 18 & 1 & 181 & & $26,70 \mathrm{I} \pm 22,963$ & 21,349 & 944 & $|56,50|$ & \\
\hline Sex & & & & & 0.823 & & & & & 0.054 \\
\hline Male & $22.1 \pm 17.1$ & 18 & 4 & 126 & & $31,324 \pm 27,637$ & 25,417 & 2,215 & $|56,50|$ & \\
\hline Female & $21.9 \pm 19.3$ & 18 & 1 & 181 & & $25,213 \pm 21,070$ & 20,396 & 944 & 133,700 & \\
\hline Insurance type & & & & & 0.003 & & & & & 0.013 \\
\hline Employed (UEBMI) & $22.9 \pm 19.9$ & 18 & 1 & 181 & & $27,450 \pm 22,378$ & 23,867 & I, 157 & $|46,48|$ & \\
\hline Resident (URBMI) & $17.7 \pm 12.3$ & 15 & 2 & 74 & & $23,514 \pm 25,190$ & 18,130 & 944 & $|56,50|$ & \\
\hline \multicolumn{11}{|l|}{ Fracture type } \\
\hline Vertebral & $19.2 \pm 16.7$ & 15 & 1 & 126 & & $21,078 \pm 22,073$ & $|I, 90|$ & 944 & 120,813 & \\
\hline Hip & $27.5 \pm 20.9$ & 22 & 5 & 181 & & $37,522 \pm 21,009$ & 38,746 & 3,284 & 133,700 & \\
\hline NVNH & $20.9 \pm 19.4$ & 17 & 2 & 177 & & $25,4|7 \pm 23, I| 12$ & 20,722 & 949 & $|56,50|$ & \\
\hline Multiple fractures & II. $.7 \pm 4.0$ & 11 & 8 & 16 & & $27,336 \pm 32,392$ & $|4,40|$ & 3,410 & 64,197 & \\
\hline Missing & $|7| \pm 7.0$. & 17 & 5 & 31 & & $13,360 \pm \mid 4,579$ & 7,910 & $\mathrm{I}, \mathrm{I} 57$ & 49,471 & \\
\hline
\end{tabular}

Note: Exchange rate $=\mid \mathrm{RMB} / \mathrm{CNY}=0.16$ USD.

Abbreviations: N, number of patients in group; SD, standard deviation; Min, minimum; Max, Maximum; UEBMI, Urban Employee Basic Medical Insurance; URBMI, Urban Resident Basic Medical Insurance; NVNH, nonvertebral/nonhip; RMB, Renminbi; CNY, Chinese Yuan; USD, United States dollar.

type and by major socioeconomic characteristics from 2008-2010 that can be used in economic analyses. Some important limitations included the small sample sizes in some geographic areas (central and west areas, prefectureand subprefecture-level cities, and county-level cities). The CHIRA database does not include the rural areas; therefore, it is not representative of rural China. Also, the $P$-values presented were not adjusted for multiplicity. Subgroups were analyzed by sex and age, but due to the cross-sectional nature of our inpatient data, it was not possible to analyze subgroups based on patient histories, such as previous fracture, cumulative glucocorticoid exposure, or other clinical risk factors for fracture, or to capture follow-up costs, such as readmission costs. In addition, because data from the CHIRA database are cross-sectional, it is not certain if the 830 patients were mutually exclusive. However, given that these patients were from a database that randomly selected from urban cities across China, the chance of the same patient having a fracture twice (or more) is very low. We did not adjust our cost estimates for inflation; however, changes in the Consumer Price Index, during the periods of 2008-2009 and 2009-2010, were $-0.7 \%$ and 3.3\%, respectively. Therefore, these adjustments have only negligible effects on the results. We included only those patients with a formal osteoporosis diagnosis in their medical claims, which may have led to the exclusion of legitimate, but unidentified, osteoporosis patients. Although potentially conservative, this definition was necessary to identify fractures most likely due to osteoporosis. The impacts of using alternative definitions of osteoporosis on hospital
LOS and cost estimates, however, should be addressed in future studies.

Rising costs in health care are being seen in nearly every market around the world. As in other markets, in mainland China, the population is aging and more expensive health care technologies are being utilized, which may be contributing to higher health care costs. However, it is beyond the scope of this study to clearly identify and examine the determinants of these rising costs. Future research is needed to extend the current study to assess longer-term trends in costs, full fracture episode costs, and the potential underlying factors behind these costs in mainland China.

\section{Conclusion}

Our study used recent, nationally representative, crosssectional data to provide more accurate estimates on the costs of osteoporotic fractures and trends over a 3-year period in mainland China. These new estimates are an important contribution toward understanding the potential economic burden of osteoporotic fractures in mainland China. Due to the anticipated fast-aging population in mainland China and the rising trend in hospital costs, the economic burden of osteoporotic fracture is expected to rapidly increase in the future. Proper medical management and societal precautions, as well as prevention of falls in the home, may reduce the economic burden of osteoporotic fractures.

\section{Acknowledgments}

This study was sponsored by Eli Lilly and Company. We would like to acknowledge the study investigators for 
collecting the data. We would also like to acknowledge Eli Lilly staff and support including affiliates, patients, families, and health care workers.

\section{Disclosure}

YY, WY, YC, and RB were full-time employees of Eli Lilly and Company. HN was a full-time employee of inVentiv Health Clinical, LLC, and was financially supported by Eli Lilly and Company for this work. FD, JL, and JZ report no conflicts of interest in this work.

\section{References}

1. Dai K, Zhang Q, Fan T, Sen SS; Osteoporotic Hip Fracture in China Study Team. Estimation of resource utilization associated with osteoporotic hip fracture and level of post-acute care in China. Curr Med Res Opin. 2007;23(12):2937-2943.

2. Luo LZ, Xu L. [Study on direct economic-burden and its risk factors of osteoporotic hip fracture]. Zhonghua Liu Xing Bing Xue Za Zhi. 2005;26(9):669-672. Chinese.

3. Huang Y, Zhu B, Zhang H. [Expenses on hospitalization in patients with hip ministry fractures from 1998 to 2003]. Chinese Journal of Osteoporosis. 2005;11(2):195-198. Chinese.
4. Cheng ZA, Lin DK, Liu DB, et al. [A 10-year-review (1998-2007) on 3449 cases of osteoporotic hip fractures: trend of hospitalization and inpatient costs]. Zhonghua Liu Xing Bing Xue Za Zhi. 2008;29(11): 1128-1131. Chinese.

5. Pike C, Birnbaum HG, Schiller M, Sharma H, Burge R, Edgell ET. Direct and indirect costs of non-vertebral fracture patients with osteoporosis in the US. Pharmacoeconomics. 2010;28(5):395-409.

6. Zhu H, Fang J, Luo X, et al. A survey of bone mineral density of healthy Han adults in China. Osteoporos Int. 2010;21(5):765-772.

7. United States Census Bureau [webpage on the Internet]. International data base. Washington, DC: United States Census Bureau; August 28, 2012. Available from: http://www.census.gov/population/international/data/idb/ region.php? $\mathrm{N}=\% 20$ Results $\% 20 \& \mathrm{~T}=10 \& \mathrm{~A}=$ separate $\& \mathrm{RT}=0 \& \mathrm{Y}=2010$, $2011,2012,2013,2014,2015,2016,2017,2018,2019,2020,2021,2022$, $2023,2024,2025,2026,2027,2028,2029,2030 \& \mathrm{R}=-1 \& \mathrm{C}=\mathrm{CH}$. Accessed October 30, 2014.

8. Kruskal WH, Wallis WA. Use of ranks in one-criterion variance analysis. J Am Stat Assoc. 1952;47(260):583-621.

9. Li H, Liu GG, Glaetzer C. Financing innovative medicines in mainland China: the role of commercial health insurance. Chinese Studies. 2013; 2(3):128-133.
ClinicoEconomics and Outcomes Research

\section{Publish your work in this journal}

ClinicoEconomics \& Outcomes Research is an international, peerreviewed open-access journal focusing on Health Technology Assessment, Pharmacoeconomics and Outcomes Research in the areas of diagnosis, medical devices, and clinical, surgical and pharmacological intervention. The economic impact of health policy and health systems

\section{Dovepress}

organization also constitute important areas of coverage. The manuscript management system is completely online and includes a very quick and fair peer-review system, which is all easy to use. Visit http://www.dovepress.com/testimonials.php to read real quotes from published authors. 